\title{
Social Innovation Assessment? Reflections on the impacts of social innovation on society - Outcomes of a systematic literature review
}

\section{¿Evaluación de la innovación social? Reflexiones sobre los impactos de la innovación social en la sociedad - Resultados de una revisión sistemática de la literatura}

\author{
Georg Mildenberger ${ }^{*}$, Gudrun-Christine Schimpf ${ }^{1}$ and Jürgen Streicher ${ }^{2}$ \\ ${ }^{1}$ CSI - Centre for Social Investment, Heidelberg University, 69115 Heidelberg, Germany \\ ${ }^{2}$ Joanneum Research, Institute for Economic and Innovation Research, A-1090 Vienna, Austria. \\ juergen.streicher@joanneum.at \\ *Correspondence: georg.mildenberger@csi.uni-heidelberg.de
}

\begin{abstract}
Today we face many societal problems, such as climate degradation, energy shortages, increasing inequality, and demographic change. Solutions for these problems require far-reaching changes and new and untried approaches. Social Innovation (SI) could be a significant factor in tackling the challenges to come. The 'reflection on the long-term effects of social innovations' is a relatively new topic but is attracting growing interest. While technology assessments are regularly used to study the consequences of technical innovations, similar assessments for social innovations are rare. This paper explores and analyses the current state of theoretical, conceptual work on the assessment for SI and their consequences, related concepts, and relevant activities. Perspectives and options for further developments in this field are derived. The method used is a structured literature review. The results show that scientific research concerning the assessment of the consequences of social innovations seems to be still in its infancy. The boundaries between established topics (such as sustainability, user orientation, including social entrepreneurship) and newer concepts are fluid. However, alongside the different approaches and views, a certain convergence of perspectives with regard to the consequences and effects of (social) innovations can be observed. Similar questions and issues are dealt with using similar approaches and methods, and are sometimes confronted with similar obstacles.
\end{abstract}

Keywords: social innovation; structured literature review; impact; assessment; dark side; reflections; consequences; measurement.

Resumen: Hoy enfrentamos problemas sociales como la degradación ambiental, carencias energéticas, creciente desigualdad y cambio demográfico. Las soluciones para estos problemas requieren cambios profundos y enfoques nuevos. La Innovación Social (IS) podría ser un factor significativo para abordar los desafíos venideros. La "reflexión sobre los efectos a largo plazo de la innovación social" es un tema relativamente nuevo, pero suscita un interés creciente. Si bien las evaluaciones tecnológicas se utilizan regularmente para estudiar las consecuencias de las innovaciones técnicas, otro tipo de evaluaciones son raramente utilizadas. 
Este artículo explora y analiza el estado actual del trabajo teórico y conceptual sobre la evaluación de la IS y sus consecuencias, conceptos relacionados y actividades relevantes. También se obtienen perspectivas y opciones para futuros desarrollos en este campo. El método utilizado es la revisión de la literatura estructurada. Los resultados muestran que la investigación científica sobre la evaluación de las consecuencias de las innovaciones sociales parece estar todavía en sus inicios. Los límites entre los temas establecidos (la sostenibilidad, orientación al usuario, emprendimiento social) y los conceptos más nuevos son fluidos. Sin embargo, junto a los diferentes enfoques y visiones, se puede observar una cierta convergencia de perspectivas en cuanto a las consecuencias y efectos de las innovaciones (sociales). Las cuestiones y problemas similares se abordan utilizando enfoques y métodos similares $\mathrm{y}$, a veces, se enfrentan a obstáculos similares.

Palabras clave: innovación social; revisión de literatura estructurada; impacto; evaluación; lado oscuro; reflexiones; consecuencias; medición.

\section{Background to the study ${ }^{1}$}

The use of future technologies (digitization, Industry 4.0, green energy, etc.) will play a key role in overcoming major social challenges such as demographic change, sustainable energy supply or scarcity of resources. However, technical progress alone is only part of the solution. Social Innovations (SI) are important as well to respond to the challenges with fundamental social and societal changes. SI are seen as a driving force and driver of social change. They are new, creative ideas, paths and measures for dealing with social and societal challenges. To better understand and investigate the consequences that (new) technologies have for people, the environment and society, a specific field of research has been established in the form of technology assessment. Using scientific methods, technology assessment attempts to identify, assess and evaluate potential opportunities and risks as early and systematically as possible. This includes direct, indirect, unintended and long-term effects of implementing new technologies. In addition to technological and economic aspects, political, cultural and social consequences are increasingly coming to the fore.

Thus, the question this paper seeks to answer is whether in the nascent field of SI a similar discourse can be found as well as research about the - intended and unintended - consequences of SI. More specifically this paper is dealing with questions such as: are these consequences considered beforehand or only in retrospect? Do scientific methods already exist to analyse, assess, or measure impact ex-post and/or ex-ante? Since both technical and social innovation can have unintended or unexpected consequences, actors and political decision-makers alike should be interested in learning about relevant developments and intervening where necessary, especially when supporting SI implementation.

This paper is based on a study commissioned by the German Federal Ministry of Education and Research. It is structured as follows: chapter 2 briefly outlines the goals and developments in technology assessment and discusses its relationship to social innovations. Chapter 3 introduces the method chosen, a systematic literature review, provides information on the process and its outcome. Chapter 4 reports on the scope and types of the identified literature, presents the subject areas and concepts that can be delimited from it, and discusses topics regarding the (negative) consequences of social innovation. Chapter 5 presents recently completed projects that address questions of estimating and evaluating SI, including relevant approaches and concepts. Finally, in chapter 6, conclusions and some recommendations are outlined.

${ }^{1}$ The research was funded by the German Federal Ministry of Education and Research. 


\section{Innovations and the assessment of their consequences}

The topic of innovation was first addressed in research, primarily from an economic perspective, but then also in the context of the history of technology (initially strongly personal, but then also artefact-related) and in the technical sciences (with a view to an invention theory). The main focus was on considerations of the systematic control of technological development in the context of emerging large-scale research with a view to applications, and later also questions of technology transfer. This development was triggered by the major development projects of the Second World War (nuclear weapons, high-frequency technology/radar). The Sputnik shock led, among other things, to the development of a differentiated innovation indicator. This was intended to help identify the key factors that promote innovation and make them accessible for political control. In the late 1960s, the negative consequences of scientific and technological progress were also addressed, initially primarily with regard to environmental damage.

All this led to the development of technology assessment with the aim of better understanding and assessing the intended and unintended consequences of new or already established, possibly improved technologies. In addition, for the future development of the respective technologies environmental, economic, social, cultural, and psychological effects should be analysed and evaluated. Based on this, recommendations for politics and other decision makers are derived (Fuchs, 2001).

SI is a more recent topic, but similar developments can be observed. After an initial phase of case studies and biographically oriented social entrepreneurship research, more fundamental topics are now increasingly being addressed. On the one hand, these are more comprehensive historical studies that reveal the long-term processes and the transforming power of social innovation (Avelino et al., 2019; Nicholls \& Ziegler, 2019; Westley et al., 2017). On the other hand, work is being done on specific indicator systems based on, but also differentiated from, the 'classical' innovation indicator system (Kleverbeck et al., 2019a; Kleverbeck et al., 2019b), and on questions of innovation clusters and regional innovation systems that are intended to produce knowledge for decision-makers. Research on SI lags behind classical technology and innovation research but uses some of their instruments and concepts, adapting them to the new topic.

It is therefore plausible to ask whether technology assessment also is mirrored in the debate on SI and whether technology assessment can serve as a model for methodologies or whether SI requires its own instruments.

Technical innovation and social innovation are not opposites but part of social development. Recent technology assessments take social changes into account more than before (Lösch et al., 2016), especially when considering far-reaching visions of the future in technology development and innovation processes. But it is still unable to focus on social changes in the context of SI. This could be because many social innovations are only loosely linked to technological development or even precede it and can be regarded more as its triggers (Schimpf et al., 2019).

\section{Method: Systematic Literature Overview}

A systematic literature review compiles literature on a topic based on clearly defined criteria. However, research on social innovations is an inter- and transdisciplinary endeavour. Not only the reflection but also the "production" of SI is based on a wide variety of actors and cannot be assigned to the market, state, or civil society. This creates some difficulties for the systematic literature review. It is not entirely clear where reports on such approaches are published. Therefore, a very broad search must first be conducted to find relevant literature on the topic of SI, which can then be filtered to determine whether it contains approaches for an impact assessment. The main steps of the systematic literature review are outlined below. 


\subsection{Scoping Review and databases}

First, an unsystematic, explorative literature search was carried out. The aim was to gain a first impression of the current literature and of the scope of the available results for answering the questions. While a systematic literature review is typically based on the relevant subject databases, this scoping review was initially implemented using a large number of databases and repositories with a high frequency of use. The main reason for this was the assumption that, given a lack of a clear definable, specific academic literature, corresponding discussions take place and are documented in different places. The search terms were initially compiled from general knowledge of the research landscape and then supplemented and refined in the scoping review course to sharpen the accuracy.

Second, the search strategy was refined, and the databases and repositories narrowed down. As the field is still young, and because many works have not yet been published in the disciplines' mainstream outlets, databases that catalogue so-called grey literature were included. By accessing and comparing the literature found in this way, a better assessment of possible distortions in the relevant literature was possible, which contributed to reducing the publication bias. At the end, the following databases and repositories were used for this research: Business Source Premier, EconLit, Web of Science, Google Scholar, OpenGrey, and WorldCat (originally, a German language database was included. For this paper, we disregarded all papers found in German).

\subsection{Search terms, inclusion and exclusion criteria}

The systematic literature search took place between March and April 2020. For this purpose, search terms were linked to search strings to cover the subject area's various facets. The strings were assembled using Boolean operands (AND, NOT, OR). The search strings were then used to search in the fields title, abstract and keywords, depending on the database or repository.

The first step was to find those records in the databases that were actually in the relevant subject area of SI. For that a search was conducted for "social innovation" and, in addition, for different variants of "social entrepreneurship" and "social enterprise". Additionally, the search terms "responsible innovation" and "transformative innovation" were included. The different variants were tested for their frequency, and the effect of different spellings and approaches was also examined. To form a "search string 1" the search terms were linked with OR: "social innovation" OR "responsible innovation" OR "social ent" OR "transformative innovation".

Similarly, "search string 2" was constructed. The following search terms were included in this string, all of which refer to impact measurement/recording methods or to a view/reflection with a further focus. These were again linked with OR: "effects of", "advantages", "ambiguity", "ambivalence", "analysis ex*", "assessment", "benefits and costs", "dark side", "digit", "digital", "disadvantages", "measurement", "ex ante", "forecast"”, "foresight", "forward looking", "impact", "indicators", "metrics", "method"”, "outcome", , reflections on", "scaling", "shortcomings of", "social benefit analysis", "social collateral", "social impact", "strategic framework", "technology assessment", "transformative" and "consequences".

The individual expressions were tested individually or in combination with search string 1 and finally linked together to search string 2 . Test runs were carried out with each search string, and random samples were taken to check the accuracy of hits and, at the same time, train the employees in judging papers.

To reduce the number of hits at an early stage, it was decided to limit the search results to the English language. Further limitations of the search (e.g., peer review, only academic journals, reception) were not made in advance in order to cover the literature in question as broadly as possible. Application of the broad-based inclusion criteria (i.e., consideration of the topics social innovation, responsible innovation, transformative innovation, and the topic area social entrepreneur/social entrepreneurship produced a significant amount of results. Hence, 
four exclusion criteria were defined to remove less informative works. They were: (1) SI is not a central theme, (2) impact assessments or effects is not a central issue, (3) no full publication is available and (4) only a single case study/ies are reported/discussed.

\subsection{Sample creation and selection of literature}

A population of approx. 6,200 titles was initially surveyed, of which approx. 300 were without an abstract. This population was subsequently transferred to the free application "Rayyan QCRI"2. The population was evaluated by two reviewers each based on the titles and abstracts and the inclusion and exclusion criteria were applied. Unsuitable hits were rejected. Through this selection and evaluation process, the texts found were initially reduced to about $10 \%$ of the population (about 600 titles). Subsequently, the duplicates were (further) filtered out and, after passing through iterative loops in the team and searching for additional information (e.g., missing abstracts), irrelevant contributions were excluded, thus creating a sample of potentially relevant literature.

The final sample contained about 210 entries and was transferred to the literature manager Citavi. If full texts were not available online, they were searched and assigned. In a further step, the full texts were screened to ensure that the texts actually dealt with the underlying research question, which in some cases they were not. Only the remaining titles were read completely and analysed.

\section{Literature Report: Impact Assessment of Social Innovations}

The above described comprehensive and systematic literature review provided a good overview of the current state of research and identified relevant publications. The following is an overview of the results of the research: the types of literature identified, the topics negotiated and the consequences of SI addressed.

\subsection{Scope and types of existing literature}

Starting from the hypothesis that there is no single discipline or well-defined field of research dealing with the impact assessment of social innovations, the literature search was broadly diversified in order to find both properly published literature and grey literature from the various disciplines dealing with social innovations. This strategy worked out fine and resulted in a wide range of topics that are dealt with under the search terms used.

After several selection rounds, a sample of about 210 titles with potentially relevant literature was available at the end. These were numerous contributions from research (many of the titles found come from research projects on social innovations or their environment, such as SI-DRIVE, SIMPACT, CrESSI, TEPSIE, TRANSIT, and WILCO, to name but a few), but fewer from practice. The plethora was journal articles, contributions to anthologies, grey literature (mainly project-related publications), and manuals made up for the smaller part with only a few monographs. In the case of anthologies, there are those that deal with innovation as a research field and also address SI in this context, as well as volumes that are dedicated to SI and include many interesting individual case studies. The latter only marginally, perhaps in an essay, take a look at the dark side (in the sense of unintended consequences) of social innovations.

What topics are covered in the literature found? A large part of the titles deals with methods of research in the field of SI, a few other titles present methods that can be used to assess the consequences or impacts of SI. The impact assessment of SI is also the explicit subject of some titles. However, the literature analysis also showed that here, different from the field of technology assessment, studies on social entrepreneurship or on (social) impact measurement, no stable and delimitable discourse has yet been established. It is no surprise that further research is demanded here. A few authors also deal with the requirements that are or should be

${ }^{2}$ Developed and provided by the Qatar Computing Research Institute. Online at: https://rayyan.qcri.org 
placed on the impact assessment of SI (Albuquerque \& Rocha, 2019; Anania \& Passani, 2014; Dhondt et al., 2016; Moody et al., 2015; Wruk et al., 2019).

In many cases, titles appeared to be suitable in the first selection rounds due to the assigned keywords, the use of programmatic sounding titles, or abstracts raised expectations that were not met during the implementation of the study. Due to the multi-stage selection process, these titles could be sorted out bit by bit. Due to the criteria used, only a handful of titles can be regarded as attempts at impact assessment of social innovations.

\subsection{Types of literature with regard to longer-term consequences of SI}

\subsubsection{Sustainability, RRI and impact measurement}

A first approach to questions of impact assessment of SI can be found in publications that act in the broader sense of Responsible Research and Innovation (RRI). The essence of this approach is to reflect on the consequences of research and innovation and to include them in the work. However, a clear methodology on how this could be done does not seem to be available yet.

Most likely to be mentioned here are studies that carry out sustainability assessments of new technologies, etc. For this purpose, there are approaches of methods especially in the fields of economy and environment. The actual social effects in the third pillar of sustainability are clearly underdeveloped. It can be assumed that in the context of the EU taxonomy for sustainable activities some further developments will take place in this area in the coming years.

Social impact measurement methods are particularly suitable for capturing the third pillar of sustainability. Various approaches now exist for this purpose, in particular the so-called Social Return on Investment Approach (SROI), which is especially common in the UK. In most cases, however, only the social impacts of a single intervention or project are determined. Sometimes, studies are found that are broader in scope and use sophisticated designs (comparison groups) to determine the effects of one type of intervention. However, such studies are very rare. The overall social effects of innovative approaches are not considered, although a kind of extrapolation is sometimes suggested. There are more detailed reflections on methodological possibilities in this direction, but not with an explicit focus on SI (Anheier et al., 2014).

\subsubsection{Problems of Social Impact Measurement}

In the debate on Social Impact Measurement, typical problems are subsequently identified in the literature found. These are mainly methodological problems, which increase in severity the larger the area of investigation. In particular, the differentiation of observable changes in the area of investigation (also called outcomes) and the proportion of change caused by a specific intervention (impacts), the so-called attribution problem. Further challenges are the displacement of the problem to another territory or to another population group and the question of how long the observed effect is maintained (drop of).

In addition, the application of the method itself is seen as a problem, especially when a focus is placed on monetary effects or when working with the monetization of social effects. The method is justifiably criticized for its utilitarian bias, with which advantages and disadvantages can be offset, which in many areas typically led to the disadvantage or neglect of groups of the population. The calculation of social profitability no longer considers the individual, but rather the benefits of the collective.

The economization of the social sector had gone hand in hand with the development of sophisticated Social Impact Measurement. This led to the emergence of a new market in which services are offered on the basis of profitability for the providers. Furthermore, as these players 
entered the field there was a lingering danger that the state might withdraw from social policy and leave it to the discretion of providers of social services (Fougere et al., 2017).

\subsubsection{Transformative Potential of Social Innovations}

A further group of publications is emerging in the field of research on transformative (social) innovation. Here, the intention of the research is already that (social) innovation brings about social change at the systemic level. Transformative social innovation is understood here as SI that challenges, changes or replaces dominant institutions in the social context (Avelino et al., 2019).

Transformative social innovation is seen as a process that involves changes in social relations, the emergence and dissemination of new knowledge and new practices. As a result, transformative change could then emerge due to co-evolutionary interactions between changing paradigms, mental models, political institutions, physical structures and innovative developments on the ground (Avelino et al., 2019; Haxeltine et al., 2017).

However, most studies of this kind tend to be ex-post analyses that trace social change back to innovation events, but do not attempt to predict expected social changes in advance. Moreover, it remains unclear how transformation or its potential is actually to be predicted.

\subsection{Topics regarding (negative) consequences of SI}

\subsubsection{Functional and/or transformative consequences of SI}

There is little debate about the positive consequences of SI. The debate is instead on the question whether it is solely a matter of a concrete solution to a problem (functional perspective) or whether it is a more fundamental change in social (power) relationships in favour of marginalized groups in society. The diversity of definitions of social innovation is partly shaped by this dispute (BEPA, 2010; Caulier-Grice et al., 2012; Nicholls \& Ziegler, 2019).

\subsubsection{Levels of possible effects}

One can distinguish in the literature three levels at which the consequences of SI are considered. First, at the level of the individual project, where it is most likely to be a question of whether the goals of the project are achieved, i.e., the proof of concept. Second, there is the question of the dissemination of an innovation (negotiated as scaling, growing, mainstreaming and others), which usually involves a change of the original idea, so that it must be re-examined whether the purpose is still being achieved. Here, there are mainly reflections on the changes of the original intention, especially of the beneficiaries of SI (Nicholls \& Ziegler, 2019; Westley et al., 2017). Finally, a successful SI can become the norm, i.e., it can spread throughout society and reach the stage of diffusion and could induce systemic change.

So far, work on impact or impact assessment has mainly been carried out at the project level; few deal with the question of what effects a type of SI has from a more holistic standpoint. At the systemic or societal level, the effects of concrete SI are less discussed, but rather the question of what is changing in a society that relies on SI as a mode of further development.

\subsubsection{The Dark Side of social innovations}

In the field of classical innovation or technology and its constant development, there is no questioning, and therefore hardly any critical reflection on the extent to which society is changed by this mode of production. At best, such thoughts can be found in philosophical or generally critical reflections on civilization. This is different in the case of social innovations, which are still perceived as new. Here, fundamental criticism of the concept of SI is made at a general or meta-level. Here too - as in the case of Social Impact Measurement - it is observed or at least feared that the state had withdrawn or might withdraw from various social fields, 
especially concerning its responsibility for ensuring solidarity and equality of living conditions for the most vulnerable. Instead, these populations had or might become new markets, and venture capitalists had or might move into the vacuum.

Besides that, some more dangers are articulated. Most of them are closely connected to state withdrawal:

- Regulatory softening: New actors had appeared on the scene who were not subject to professional or regulatory rules. Therefore, it was not surprising when said actors were reported to have practiced wild methods at times. This led to democratic deficits and a lack of transparency (see also governance deficits below). To make matters more precarious, often, the target market of these enterprises was the most vulnerable and underrepresented population segments.

- Unequal opportunities: The increasing emphasis on SI meant that under the guise of empowerment, local actors were expected to manage their own affairs. At times this resulted in a widening disparity because now the marginalised local community had to draw on their own strained or depleted resources. This could cement existing inequalities between different regions and actors. Furthermore, constantly shifting local arrangements that result from reorganisation could result in increased transaction costs (Steen et al., 2018).

- Exaggerated confidence in the potential of social innovation: The concept of SI, as currently propagated, suffered from too much trust in SI and its advocates. It should not be expected that SI could produce universal solutions to systemic problems. Moreover, the aspect of power was underestimated. It played a decisive role in the dissemination of SI and not only the quality of the solutions found (Segnestam Larsson \& Brandsen, 2016).

- Governance deficits of social innovation: Overall, the concept of SI is ambivalent. It would be crucial also to consider the problematic aspects of SI, such as their fundamentally deviant character as well as often the conflict between social and economic benefits (Brandsen, Evers, Cattacin, \& Zimmer, 2016). SI, like innovation in general, challenged the existing rules. The modification of these rules should be carried out in the democratic process alone. It should not be left to the wild imagination of markets or other forums. The new governance arrangements in the wake of SI have led, among other things, to a loss of democracy and lack of accountability (Fougere et al., 2017; Fougere \& Meriläinen 2019; Swyngedouw, 2009).

\section{Conceptual approaches to assess SI}

Amongst all of the literature analysed, concepts and suggestions for ex-ante assessments of SI and impacts have been particularly found in the context of research work and in publications related to projects funded under the EU Research Framework Programmes (FP). Already in FP6 and FP7 of the EU as well as in the still current program Horizon 2020 some large research projects have been funded, which have dedicated or are dedicated to a better understanding of the conditions under which SI develops and their (societal) effects.

In the following, three recently completed projects are presented which - to varying degrees - also address questions of estimating and evaluating SI, discussing and, in some cases, also testing relevant approaches and concepts. It is interesting to note that relevant thematic reports (Jenson \& Harrisson, 2013; Moulaert et al., 2017). European Commission, (Jenson \& Harrisson, 2013; Moulaert, 2017) on SI at the European level have sometimes given little consideration to this topic.

- The aim of SIMPACT (http://www.simpact-project.eu) was to conduct a comprehensive analysis of a large number of SI in Europe. One focus was on ex-ante impact assessments in the context of SI. Based on well-known concepts and methods, mostly from evaluation research, the project proposes a structured process of the analysis 
following single steps. This includes the formulation of objectives, the determination or definition of the relationships between inputs, direct (outputs) and indirect effects (outcomes), the definition of the role of the actors involved (in order to achieve the objectives), the calculation of impacts, and finally a discussion of the results with the actors in order to gain insights into relevant contexts.

Different methodological tools are proposed for the different phases, such as Logic Modelling (or Theory of Change) for structuring goals and activities or SROI approaches to estimate impacts quantitatively, with reference to existing data. In order to better assess the role of the various actors and their (value) perceptions of SI in advance, a value network analysis is proposed. The lack of availability of relevant data is mentioned as a challenge. In addition to data from similar, past projects, expert knowledge should also be used.

- CrESSI (https://www.sbs.ox.ac.uk/research/research-areas/impact/creating-economicspace-social-innovation) aimed to look at medium and long-term projects, programs and policies that would promote greater equality, inclusiveness and sustainability in Europe. In addition to theoretical considerations and policy analyses, case studies in a long-term perspective were developed, which also provide information on the interaction between social and technical innovation. Different approaches to social impact measurement are presented and discussed and are also fed into the discussion of social impact bonds. In particular, the human capabilities approach is used to determine the impact of SI on the individuals involved. In a sophisticated survey design with semi-structured interviews, focus groups and structured interviews by questionnaire, a total of about 3,500 individuals were interviewed, with part of them serving as a control group. Unfortunately, it was not possible to realize a survey at two points in time, so that changes had to be determined from the participants' memories. However, the design can be applied in multiple repetitions at any time.

The methods applied are suitable for making the complex contexts of SI visible and provide important indications of factors that must also be considered in an ex-ante analysis.

- The objective of SI-DRIVE (http://www.si-drive.eu) was to improve the theoretical and empirical basis of SI and to develop recommendations for future policy strategies to strengthen the role of SI. Therefore, over 1,000 cases of SI worldwide were investigated and described. In particular, 'foresighted' or future-oriented approaches and concepts (foresight) are discussed. According to the project, relevant foresight methods include the development of literature reviews, the use of expert panels and scenarios (analyses). Other frequently used methods include future workshops, brainstorming and trend analyses as well as common methods of empirical social research (interviews and questionnaire surveys). According to the project, these and other instruments established in the foresight field could also be applied (adapted accordingly) for 'foresight' in the context of SI. Particularly suitable appear to be instruments with a distinct interactive and participatory character, such as expert panels. From a methodological point of view, forward-looking approaches to SI must consider various dimensions of (potential, future) change, including changes in contexts, (changing) demands on (social) innovation, and the barriers and success factors of SI, and how these can either prevent or foster transformative dynamics.

Also, the literature occasionally contains further, partly conceptual approaches to the analysis and evaluation of the consequences of SI. These are not unlike the procedures and methods used in (participatory) TA. In the following, some of these examples are briefly presented, with special emphasis on the facets of design:

- $\quad$ Strategic niche management (SNM) for the development and testing of SI (Witkamp et al., 2006): By providing innovative niches or shelters, niche developments can be 
experimentally developed, promoted and examined in order to generate the most extensive learning effects possible for the further development steps. In this specific case, the niche of social entrepreneurship was compared to the economic regime and civil society. In each case, the contradictory and common values were analysed. The obstacles to social entrepreneurship (or SI as a core element) identified in this way can certainly help support this niche's development.

- Creation of experimental spaces for (social) innovation: Real world laboratories are temporally and often also spatially limited test spaces to better test innovations and regulation. Social Labs are usually dedicated to concrete social problems and try to find solutions for a concrete social problem, often involving many different actors. Recently, for example, more regulatory scope has been created to test the effects of the conversion of the welfare system to basic income (Kangas et al., 2019).

- Participatory foresight for SI: Development of probable (but not predictable) visions of the future in a participatory process. In the project Tomorrow's Land, a project cofunded by the EU's Erasmus+ program, the experiences of social innovators from different countries are used to support others in their development and to exchange mutual experiences. On the one hand, important insights into different future scenarios are given and on the other hand, a learning framework defines relevant key competencies, skills and knowledge to support pioneers in the field of SI (Orazbayeva \& Dyrman, 2017). In another case, an instrument is proposed (FLUX-3D method; 'Forward Looking User Experience'), which evaluates innovative proposals according to the users' experiences. It is based on a systematic representation of user satisfaction on three levels of analysis (dimensions, indicators, variables), which should facilitate short, medium and long-term decision making.

\section{Conclusion}

SI aims to respond to social challenges and needs and to contribute to sustainable development. Similar to technical innovations, social innovations may have unintended or undesired effects, often only visible in the long run. While the reflection on the long-term effects of SI is a rather new topic, it is attracting growing interest. The aim of the underlying study was to explore and discuss the current state of theoretical and conceptual work on assessing the impact of SI, related concepts and relevant activities in research and practice.

First, the literature review found only vague references concerning a theoretical or conceptual transferability of approaches and concepts of technology assessment or similar to analyse and evaluate the consequences of SI. Moreover, no fixed set of approaches, activities or standards could be identified that were considered necessary and would have to be adhered to for an impact assessment of SI. The focus was rather on SI research methods, assessing the effects of SI and associated challenges, often embedded in discussions about social entrepreneurship and (social) impact measurement.

Secondly, in light of this, it is shown that there is a broadening discourse concerning the analysis and measurement of social and societal impacts. The discussions surrounding these impacts range from functional and transformative consequences to levels of possible effects and the so-called "dark side" of SI, the critical questioning of the (positive) assumptions and expectations associated with SI. However, the impact assessments found are typically related to the past and limited to individual projects, interventions, or organizations.

Thirdly, this work presented conceptual approaches that address questions of estimating and evaluating SI, and methods that can be applied in corresponding impact analyses. Participatory development processes and newer "foresight" approaches are increasingly finding their way into assessing SI. Suggestions for further developing existing concepts can be derived, including methodological aspects, the (participatory) involvement of relevant actors, and the preparation, planning, and consideration of the individual initial situations. 
In conclusion, it seems that, in particular compared to technology assessments, research about the impact assessment of SI is in its early stages. The boundaries to related topics (sustainability, user orientation, social entrepreneurship) or newer concepts (e.g., transformative innovation) are fluid. It is the opinion of the authors of this paper that new concepts are needed to better record and evaluate the (potential) effects of SI, for example, by using and expanding approaches that have been built around the concept of "Social Impact Measurement". Particularly, the aim should be - as it is in technology assessment - to broaden the perspective to include the effects and impacts of SI at the systemic or overall societal level. Importantly, the fundamental public and political interest in the topic under consideration and the consequences to be considered plays an important role. The selection of topics (to be) analysed in the course of an impact assessment is mostly selective and depends on political attention cycles, which might pose a challenge for the development of an impact assessment of SI. Hence, further work is needed to establish the foundations and to develop standards.

\section{References}

Albuquerque, C. P., \& Rocha, S. (2019). Third Sector and Social Innovation in Local Communities in Portugal: Dilemmas Concerning Framing and Measurement of Social Impact. In New Paths of Entrepreneurship Development (pp. 257-281). Springer, Cham. DOI: https://doi.org/10.1007/978-3-319-96032-6_13

Anania, L., \& Passani, A. (2014). A Hitchhiker's guide to digital social innovation [paper] 20th ITS Biennial Conference, Rio de Janeiro.

Anheier, H.K., Krlev, G., Preuss, S., Mildenberger, G., Bekkers, R.H.F.P., Mensink, W., Bauer, A., Knapp, M., Wistow, G., Hernandez, A., \& Adelaja, B. (2014). Social Innovation as Impact of the Third Sector. Deliverable of the project: "Impact of the Third Sector as Social Innovation" (ITSSOIN), European Commission - 7th Framework Programme. Brussels.

Avelino, F., Wittmayer, J. M., Pel, B., Weaver, P., Dumitru, A., Haxeltine, A., Kemp, R., Jørgensen, M. S., Bauler, T., Ruijsink, S., \& O'Riordan, T. (2019). Transformative social innovation and (dis) empowerment. Technological Forecasting and Social Change, 145, 195-206.

BEPA (2010). Empowering people, driving change: Social Innovation in the European Union. France.

Brandsen, T., Evers, A., Cattacin, S., \& Zimmer, A. (2016). The Good, the Bad and the Ugly in Social Innovation. In T. Brandsen, S. Cattacin, A. Evers, \& A. Zimmer (Eds.), Nonprofit and Civil Society Studies. Social Innovations in the Urban Context (pp. 303-310). Cham: Springer. DOI: https://doi.org/10.1007/978-3$\underline{319-21551-8 \quad 9}$

Caulier-Grice, J., Davies, A., Patrick, R., \& Norman, W. (2012). Defining social innovation. A deliverable of the project. The Theoretical, Empirical and Policy Foundations for Building Social Innovation in Europe (TEPSIE), European Commission-7th Framework Programme. Brussels: European Commission, DG Research.

Dhondt, S., Ven, H., Cressey, P., Kaderabkova, A., Luna, Á., Moghadam Saman, S., Casto, J., ŽiauberytėJakštienė, R., Van der Torre, W., \& Terstriep, J. (2016). Evaluation Toolbox - Ex-Ante Impact Assessment E Value Network Analysis for SI: Simpact Project Report. Gelsenkirchen. Available at: http://www.simpactproject.eu/publications/reports/simpact_d7.2.pdf

Fougère, M., \& Meriläinen, E. (2019). Exposing three dark sides of social innovation through critical perspectives on resilience. Industry and Innovation, 1-18. DOI: https://doi.org/10.1080/13662716.2019.1709420 
Fougere, M., Segercrantz, B., \& Seeck, H. (2017). A critical reading of the European Union's social innovation policy discourse: (Re)legitimizing neoliberalism. Organization, 24(6), 819-843. DOI: https://doi.org/10.1177/1350508416685171

Fuchs, G. (2001). Wirtschaft und Technikfolgenabschätzung-Aus der Arbeit der Akademie für Technikfolgenabschätzung in Baden-Württemberg. TATuP-Zeitschrift für Technikfolgenabschätzung in Theorie und Praxis, 10(2), 45-50.

Haxeltine, A., Pel, B., Wittmayer, J., Dumitru, A., Kemp, R., \& Avelino, F. (2017). Building a middle-range theory of Transformative Social Innovation: Theoretical pitfalls and methodological responses. European Public E Social Innovation Review, 2(1), 59-77. DOI: https://doi.org/10.31637/epsir.17-1.5

Jenson, J., \& Harrisson, D. (2013). Social innovation research in the European Union. Approaches, findings and future directions. Policy review, 978-92. Available at: 10.2777/12639

Kangas, O., Jauhiainen, S., Simanainen, M., \& Ylikännö, M. (2019). The basic income experiment 2017-2018 in Finland: Preliminary results.

Kleverbeck, M., Krlev, G., Mildenberger, G., Strambach, S., Thurmann, J.-F., Terstriep, J., \& Wloka, L. (2019). Indicators for measuring social innovation. In J. Howaldt, C. Kaletka, A. Schröder, \& M. Zirngiebl (Eds.), Atlas of Social Innovation: Vol. 2. Atlas of Social Innovation. A World of New Practices (pp. 98-101). Munich: Oekom verlag.

Kleverbeck, M., Mildenberger, G., Schröer, A., \& Terstriep, J. (2019). Regional social innovation networks. In S. M. Weber, I. Truschkat, C. Schröder, L. Peters, \& A. Herz (Eds.), Organisation und Pädagogik: Vol. 26. Organisation und Netzwerke. Beiträge der Kommission Organisationspädagogik (pp. 355-374). Wiesbaden: Springer Fachmedien Wiesbaden. DOI: https://doi.org/10.1007/978-3-658-20372-6 33

Lösch, A., Böhle, K., Coenen, C., Dobroc, P., Ferrari, A., Heil, R., Hommrich, D., Sand, M., Grunwald, A., Dickel, S., Schulz-Schaeffer, I., \& Wentland, A. (2016). Technikfolgenabschätzung von soziotechnischen Zukünften.

Moody, M., Littlepage, L., \& Paydar, N. (2015). Measuring Social Return on Investment: Lessons from Organizational Implementation of SROI in the Netherlands and the United States. Nonprofit Management and Leadership, 26(1), 19-37. DOI: https://doi.org/10.1002/nml.21145

Moulaert, F., Mehmood, A., MacCallum, D., \& Leubolt, B. (2017). Social innovation as a trigger for transformations-the role of research. Publications Office of the European Union. Brussels. DOI: 10.2777/68949

Nicholls, A., \& Ziegler, R. (Eds.). (2019). Creating economic space for social innovation. Oxford: Oxford University Press.

Orazbayeva, B., \& Dyrman, M. (2017). Tomorrow's Land: Strategic Foresight Report 2017 - Intellectual Output 1.

Schimpf, G.-C., Mildenberger, G., Giesecke, S., \& Havas, A. (2019). Trajectories of Social Innovation: Housing for All? In A. Nicholls \& R. Ziegler (Eds.), Creating economic space for social innovation (pp. 109148). Oxford: Oxford University Press. DOI: 10.1093/oso/9780198830511.003.0005

Segnestam Larsson, O., \& Brandsen, T. (2016). The Implicit Normative Assumptions of Social Innovation Research: Embracing the Dark Side. In T. Brandsen, S. Cattacin, A. Evers, \& A. Zimmer (Eds.), Nonprofit and Civil Society Studies. Social Innovations in the Urban Context (pp. 293-302). Cham: Springer. DOI: https://doi.org/10.1007/978-3-319-21551-8 
Steen, T., Brandsen, T., \& Verschuere, B. (2018). The Dark Side of Co-Creation and Co-Production: Seven Evils. In T. Brandsen, B. Verschuere, \& T. Steen (Eds.), Routledge Critical Studies in Public Management Ser. Co-Production and Co-Creation. Engaging Citizens in Public Services (pp. 284-294). Milton: Routledge. DOI: https://doi.org/10.4324/9781315204956

Swyngedouw, E. (2009). Civil Society, Governmentality and the Contradictions of Governance-beyondthe-State: The Janus-face of Social Innovation. In D. MacCallum, F. Moulaert, J. Hillier, \& S. Vicari Haddock (Eds.), Social Innovation and Territorial Development (pp. 63-78). Farnham, Burlington, VT: Ashgate.

Westley, F., McGowan, K., \& Tjörnbo, O. (Eds.). (2017). The Evolution of Social Innovation: Building Resilience Through Transitions. Cheltenham: Edward Elgar.

Witkamp, M. J., Raven, R. P., \& Royakkers, L. M. (2006). Strategic Niche Management of Social Innovation: the case of Social Entrepreneurship in the Netherlands. Working Paper.

Wruk, D., Oberg, A., \& Friedrich-Schieback, M. (2019). Quantifying the sharing economy: An approach for measuring the ecological, social, and economic effects. Gaia-Ecological Perspectives for Science and Society, 28(1), 184-189. DOI: https://doi.org/10.14512/gaia.28.S1.3

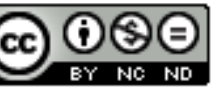

(C) Attribution-NonCommercial-NoDerivatives 4.0 International (CC BY-NC-ND 4.0) https://creativecommons.org/licenses/by-nc-nd/4.0/ 